$$
\text { 22-25 Sept: } 9
$$
W. Australia 
Specien w weess 23 Sept 89

V Sitteda - gropd4

W. Wariter 30.4 Aaral A.T?

Wivitriller - Ser

BrHE, Sin GE, Y-TMiner, Sp-ChHE R.c Rabin - Singj - also 2 wivestf

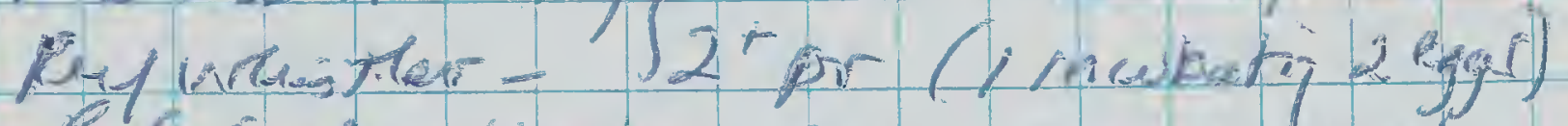

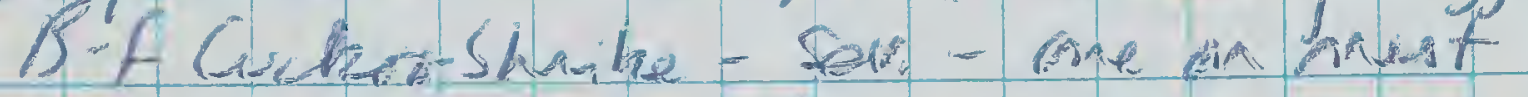

Bewbind - 3t Singing o

qi she Ta - sev: singis

slognt Purrat, PriLncen R. Galkh

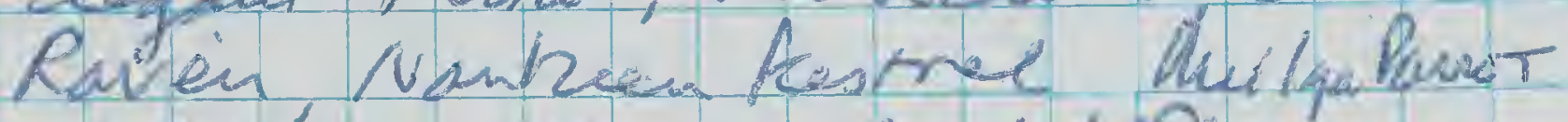

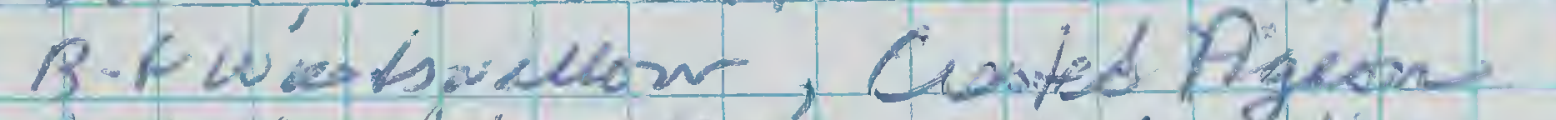

witle Wral Y-RT-bil, Weetie spr. Pandabte, Tree Martin, Magpie,

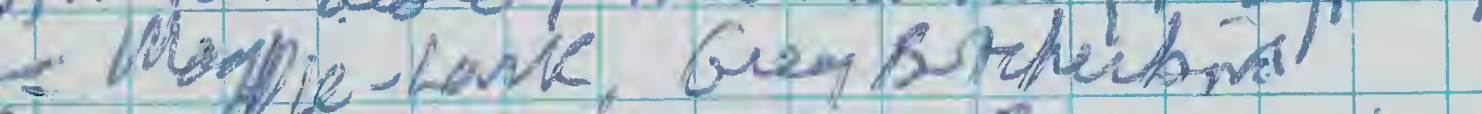

Aror steun: Ar Famtail Bu-eateg kishisher $\square$ Spolted Atarvier, Bhebreasted Wren

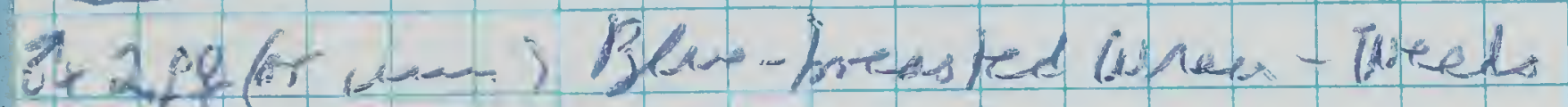
Fugr pist the saes hav.

rupres be tarok blenk freet cbert

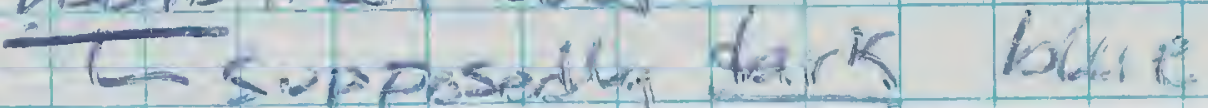

$x$

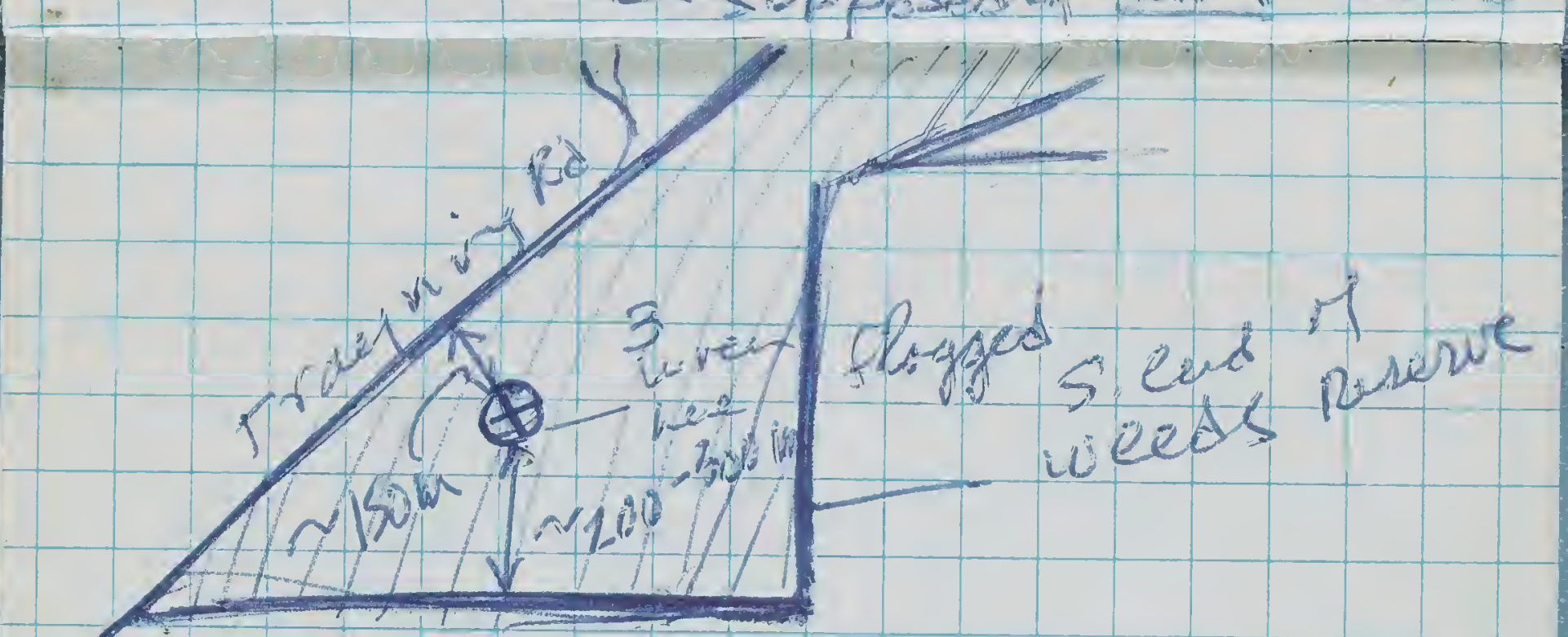

Afrexenoon

Durtapria East

louked fur Jasking Wuater hent

areacianth of N-izos looked vight bet seb flogs

Rvain forcad nust-bor pareats

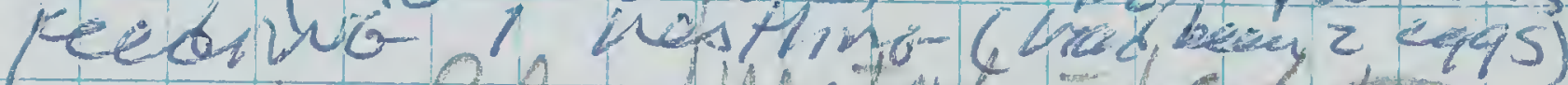
br Bewrineta

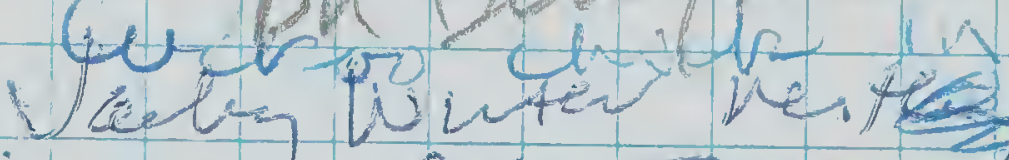

Let $01-74760$ 8.5 gim

ElA 6q-only sutal 033-27059

kiqu liy - danh blve

$\rightarrow$ tavos V. Skat-covdu'fit 2 bands an onue ly! Feet sorrg - brigut yellow nestien b.fat bewsthustin

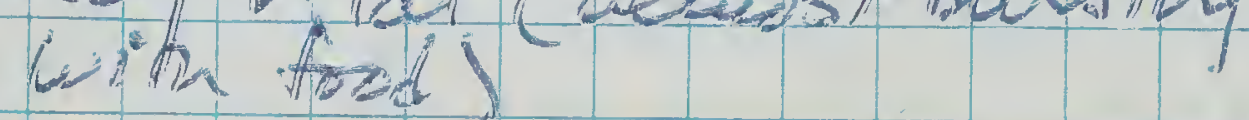


Lizands / colleded in Wreds follog for Sehyar vaniegeta - qecko $\frac{\text { Menetia }}{\text { tiny skink grey ii }}$

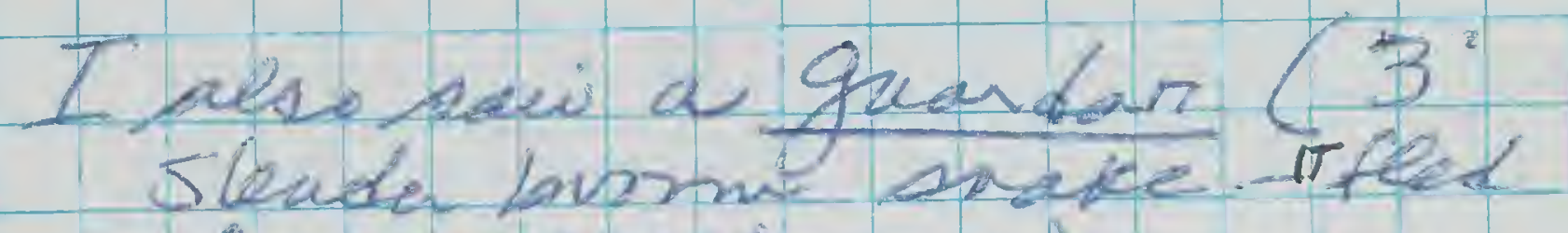
into pabit burnow)

Diftury bet the donnur alowly

Note: W. Wharber otith cunew of suyngy, hut guep fautail appran to ke. qune

$2 a 5+89$

\& Meurage Rel. Wrenter Capiner at ureeds Sust NE of wheie vatis

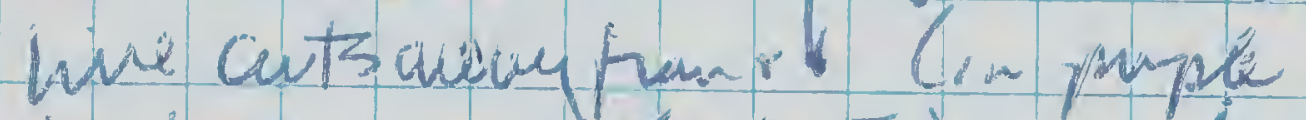

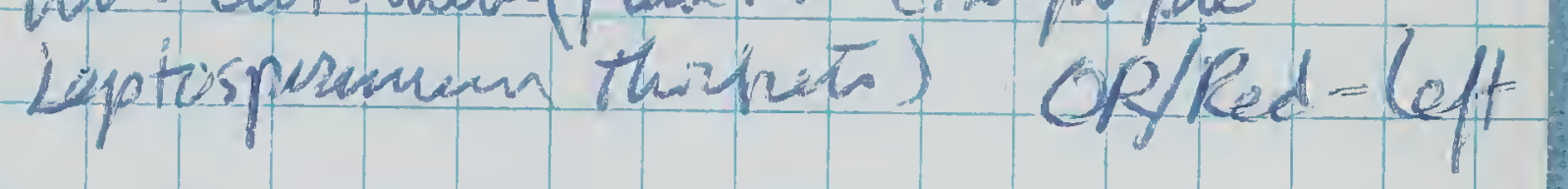
Throata uppen breasi kasuide streatuar erped dk chocolate broum

bill black

back pay worertares borea

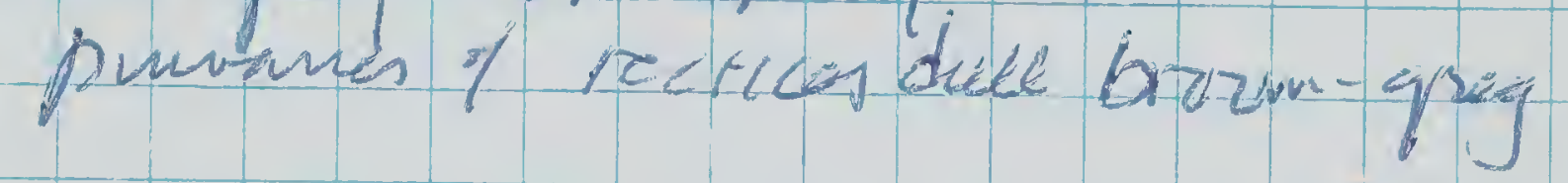

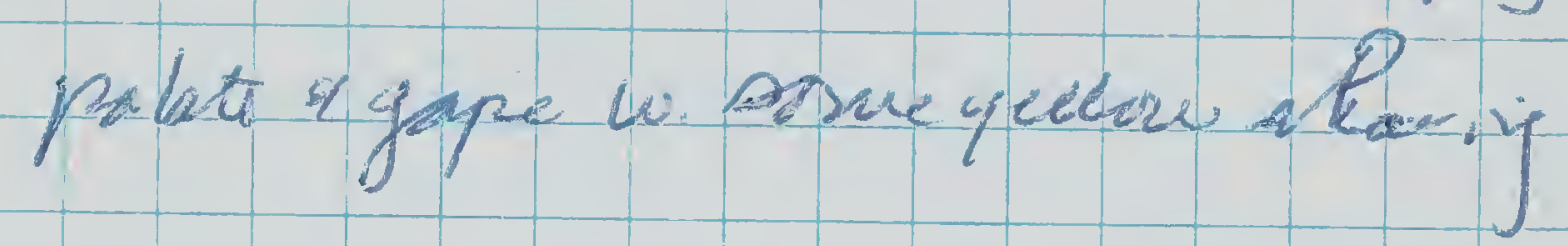




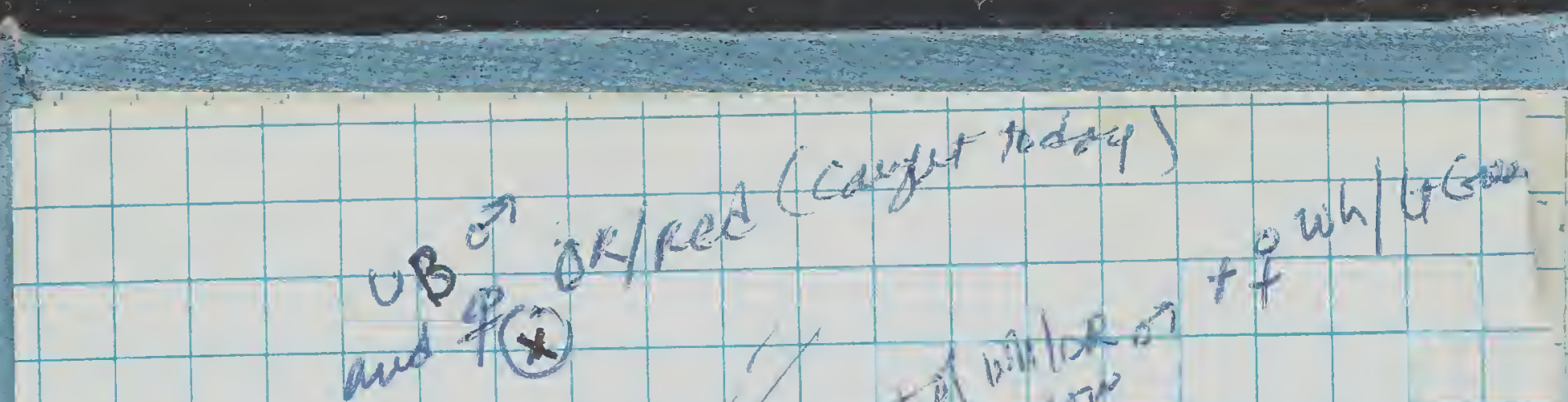
N

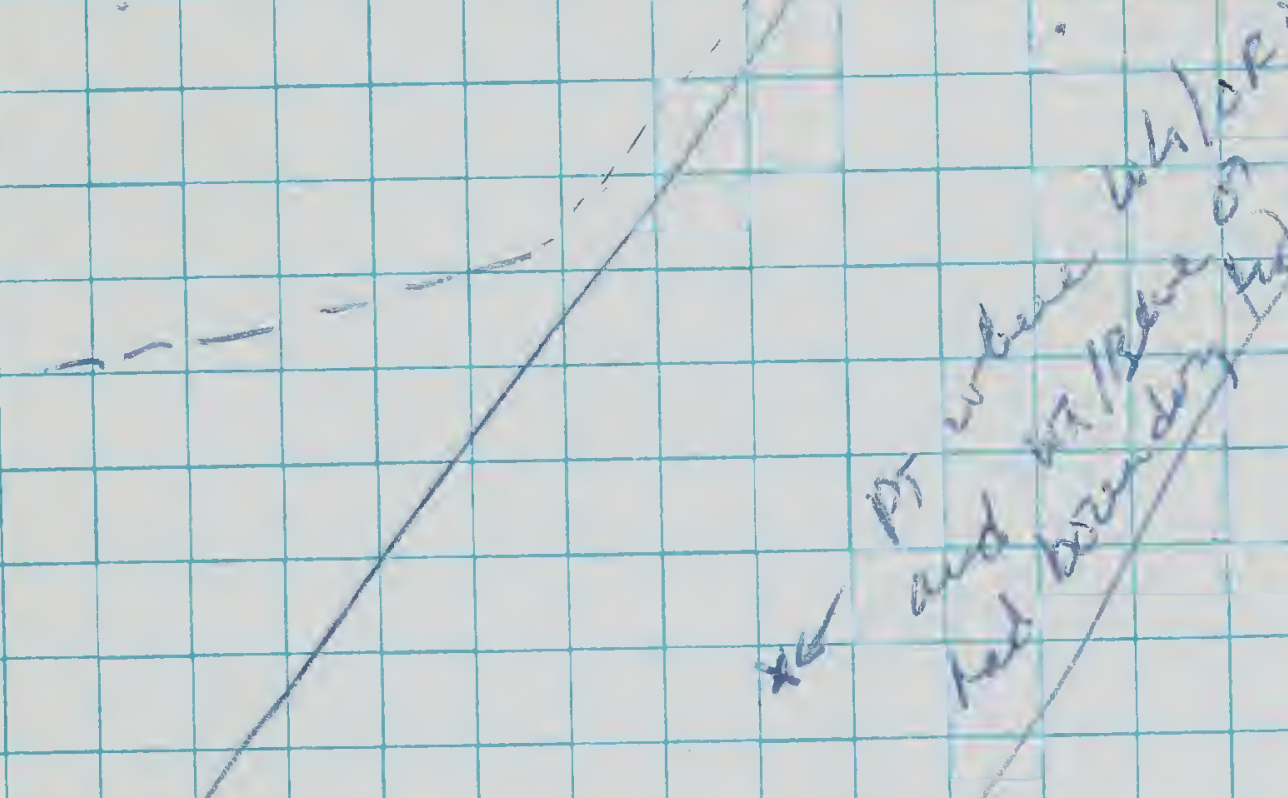

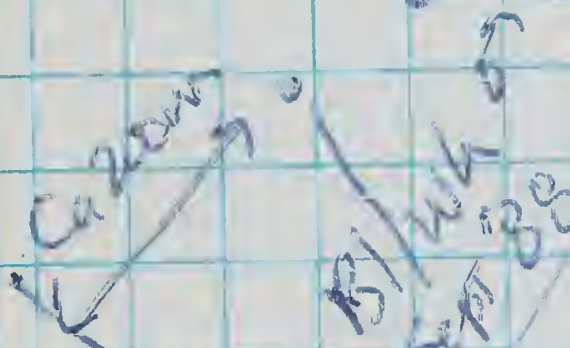

$<-140$

$>1 /$

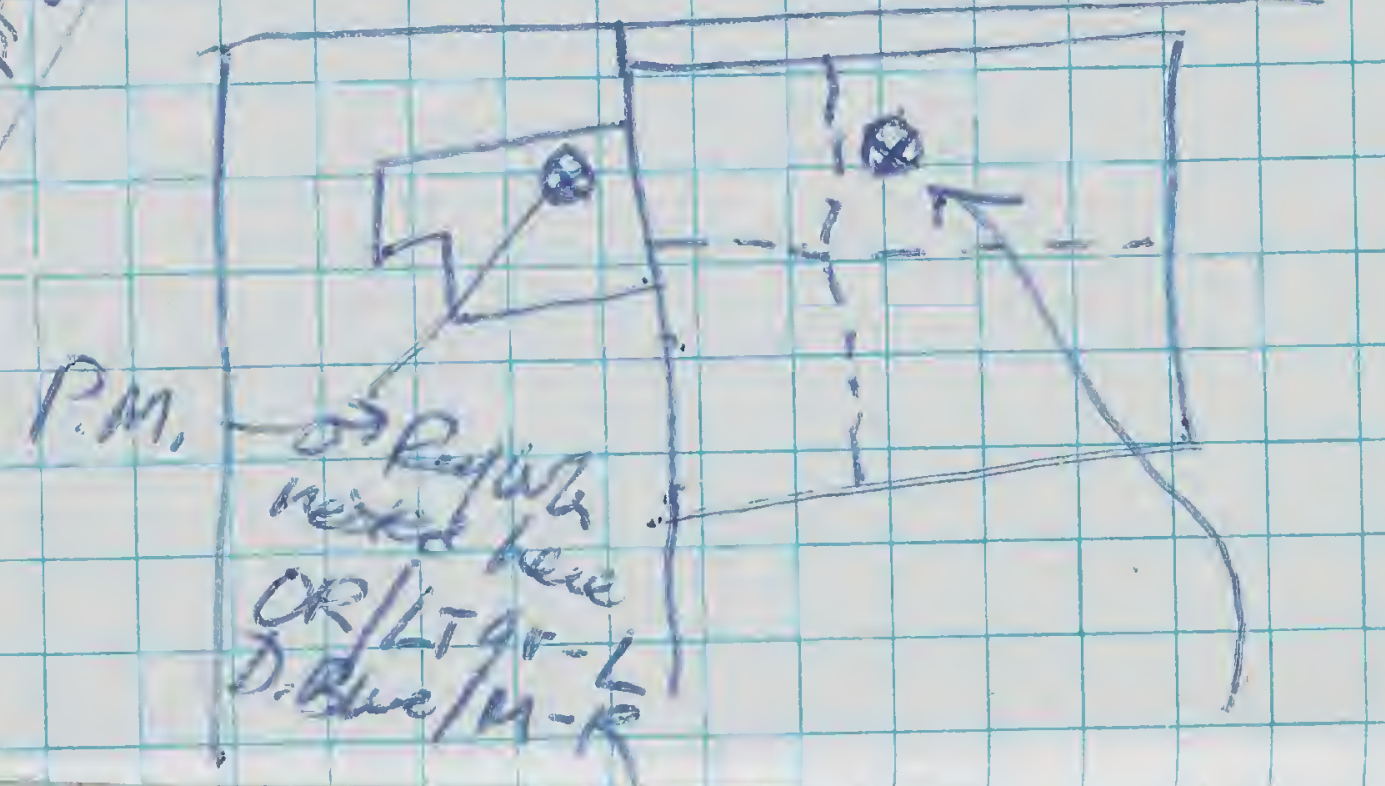

Durakoppin cast-meted 3 t ay $\rightarrow$ Reques wlister just $\mathrm{E}_{\mathrm{c}}$ of "Harrey's pertel".

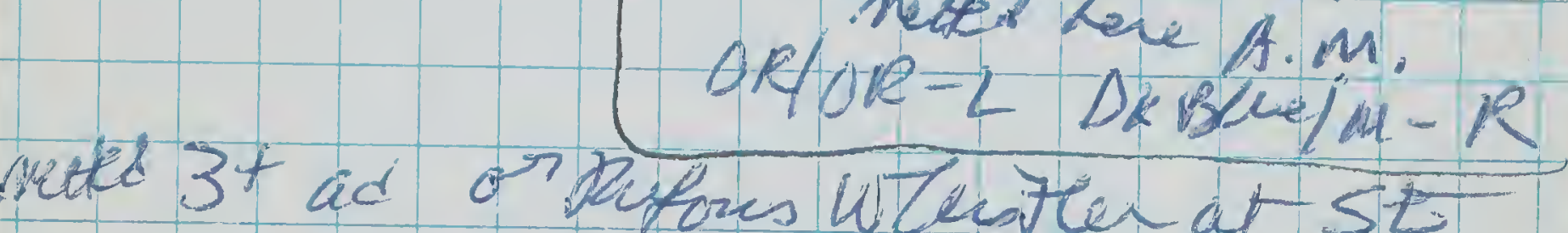 comer of Dur. West}

eye-brick rejd bill blad bach gray - kead gray gape-1patet bleve

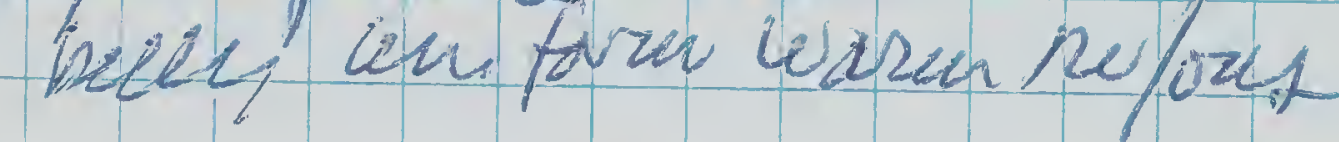

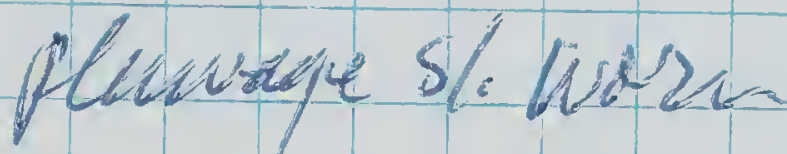


Note: distane fou Trayning-Beacon is $76 \mathrm{~km}$

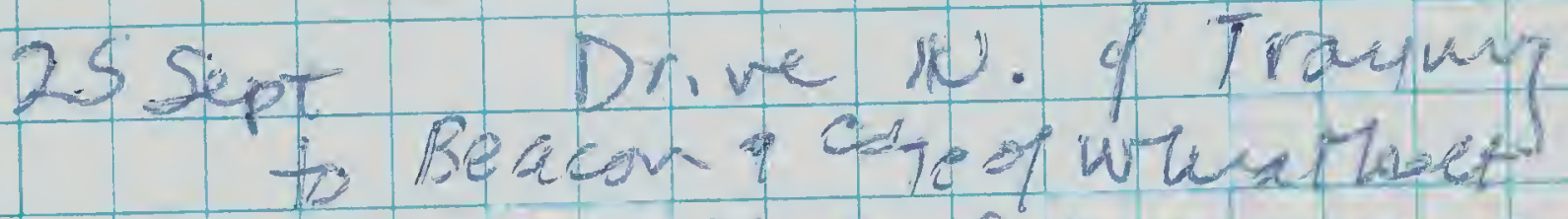

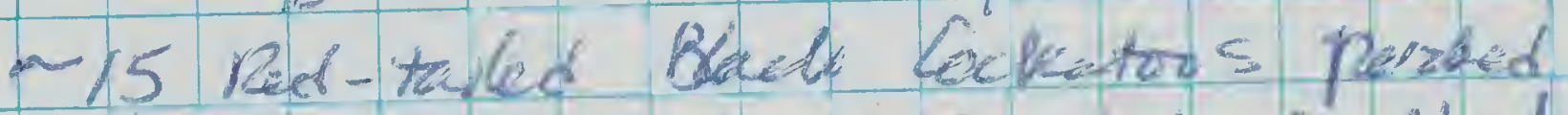
in Delze of wradeond bundur Paddack - $5 \mathrm{rem}$ 5. Bereen (arrof detaur)

cue is une millabe-hap pitodud raspirg anala - ciacas! ung heor ver slow

-98613 Bemar 47 a R,wbedgista no 706 Mallat frol ciry ird bash-yosk-jow-Cas coaderd friñy a Rele also:

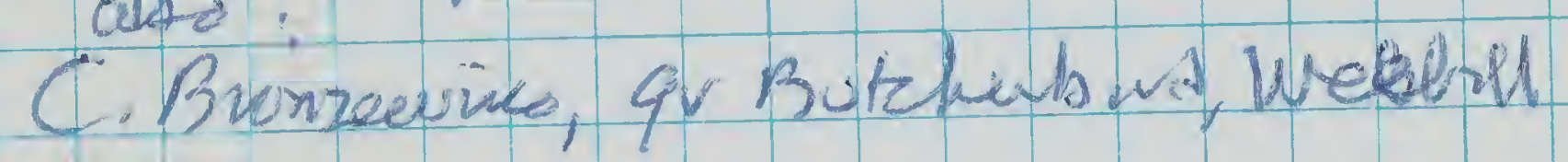
$-107$

Eaidua un usad here: pkotos Lie poneres of wild flantes

olw hivds ind Caseiua-devindel

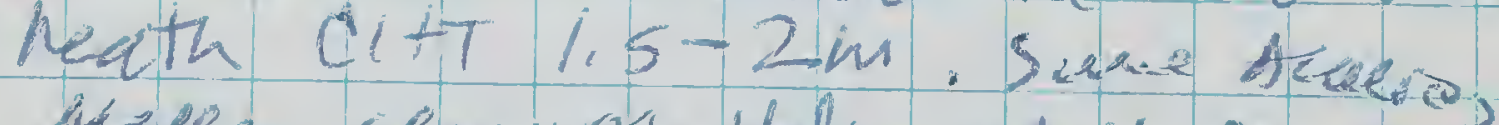
mallew clentas, halket eta to $30.4 \mathrm{~m}$ qolden What Hee - I por.

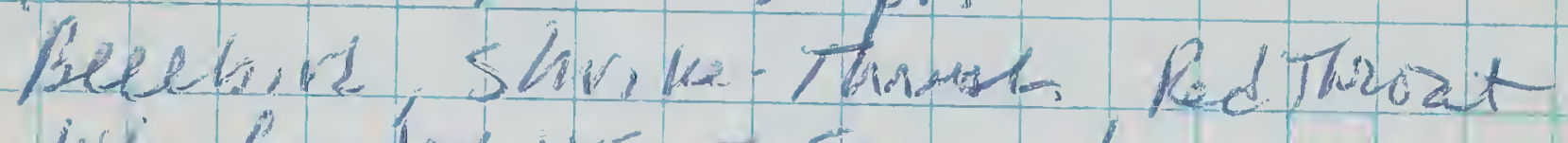
Wh- Fusaled he - Ser

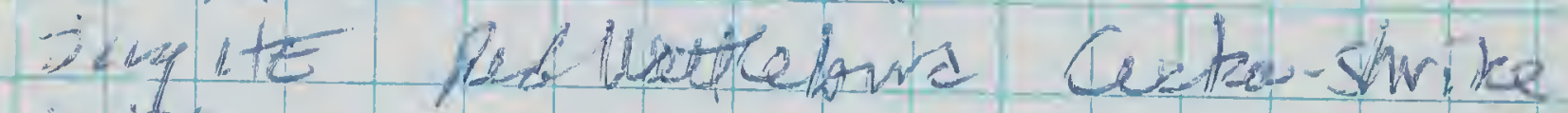

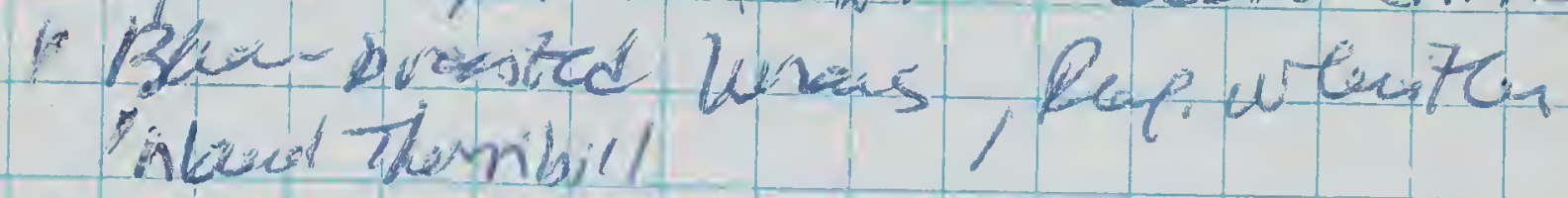

t $\quad \pi i l l$

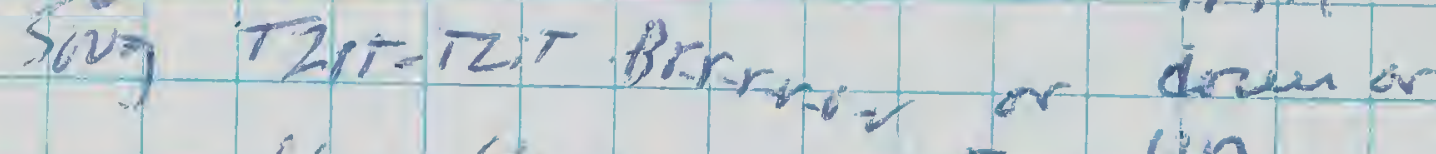
$\beta-r-r-r-r$ up

- 709 Buce kd to le Pin Gian sped keu

- 720 pervent redo

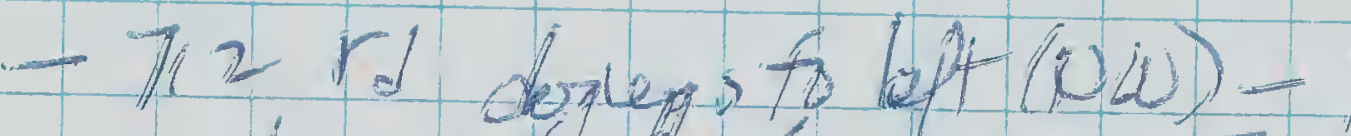

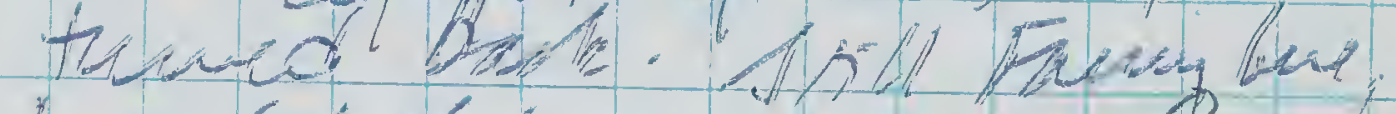

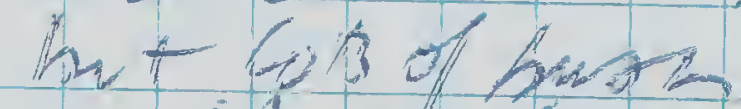
Had S. fruxd Beacan

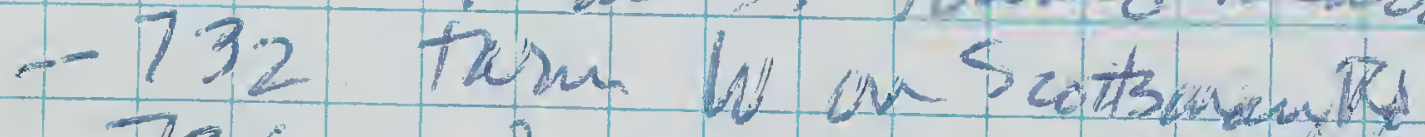

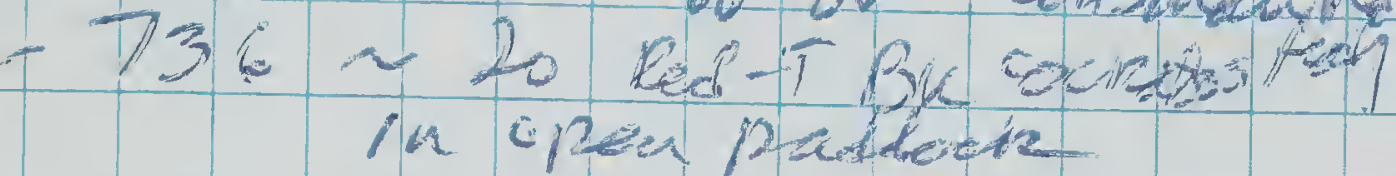

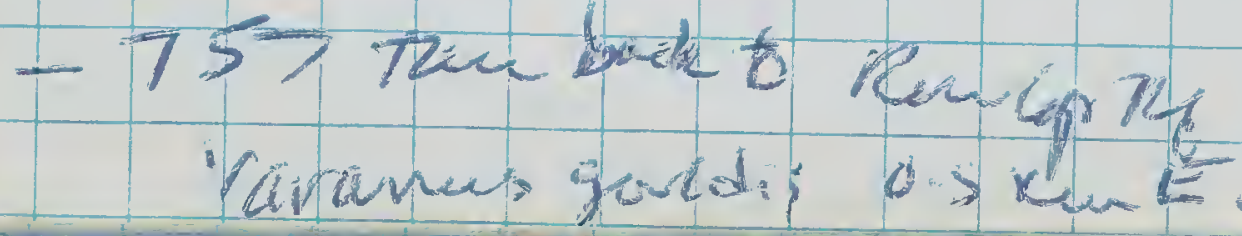




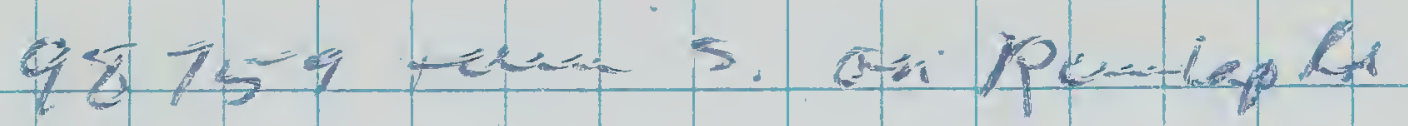

98792 then s. towand barda

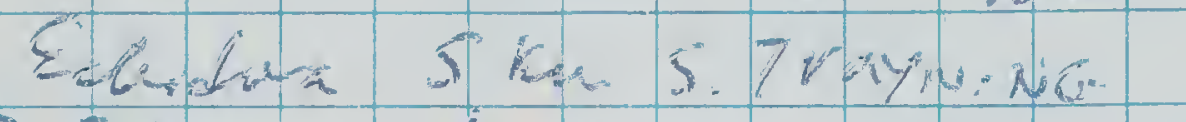

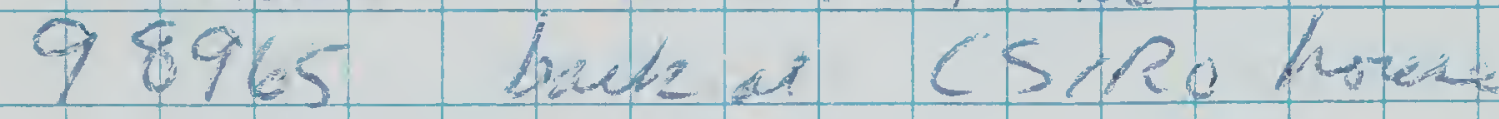

\& Coreelen tust W. Tratrini-

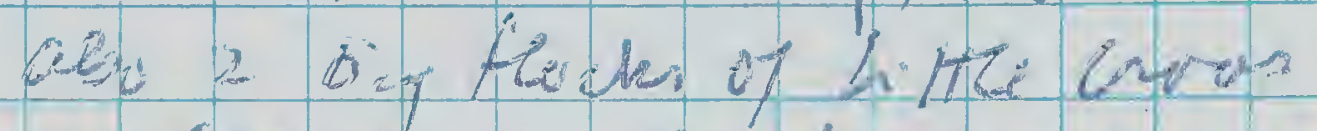

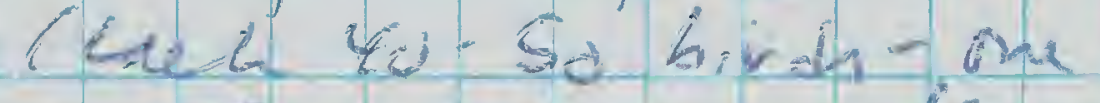

hean Traypaif, other ne Kourdas)

\section{$26 \mathrm{kpt}$ lueeds}

070 neted o Ry uraitu

mon uspor Jue been firj to netrizoen NE pwatehlive takntim on wi sile 710 .

aree spe here tody:gre

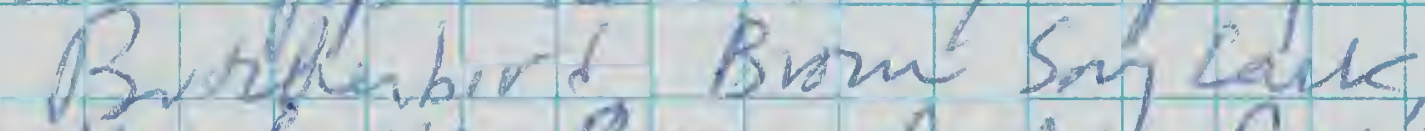
Harshed's Brome-Quckio, Pallid Cquas, pr Spini-Cheradis.

3 fee butilatind

2. W. Sur deumg youg in rest

fareed on E. bido of the rd: a

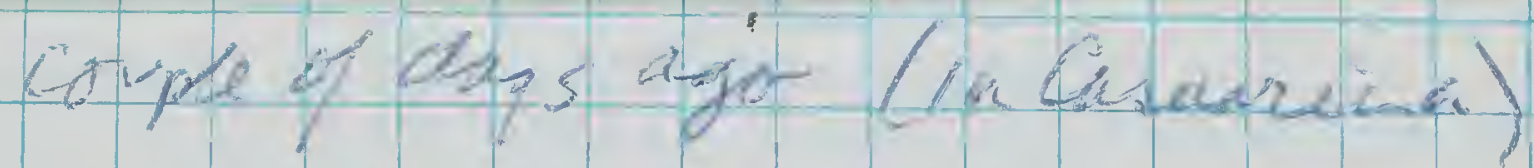

i SHEHE WEOBC

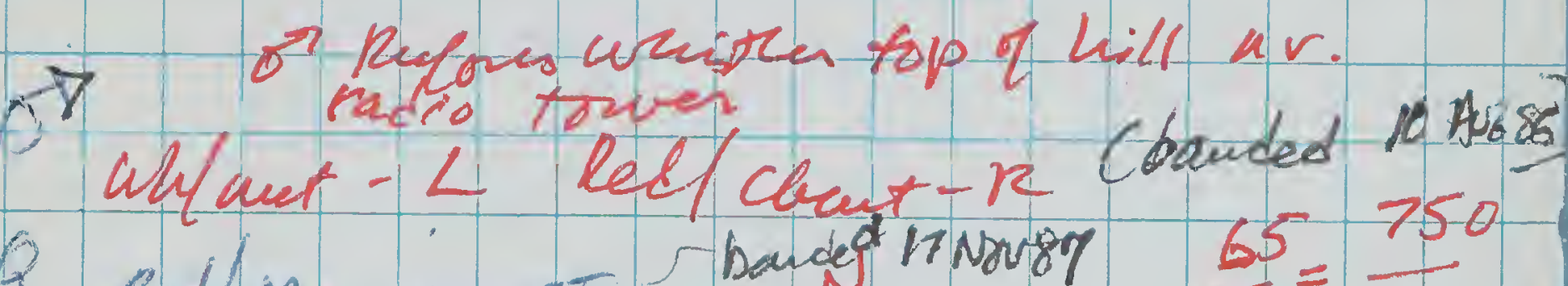

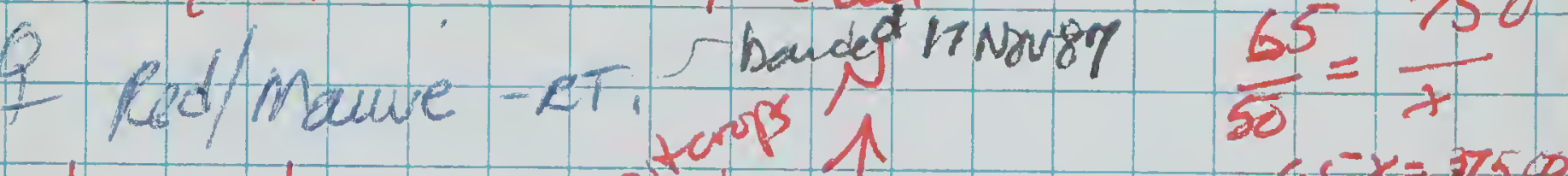

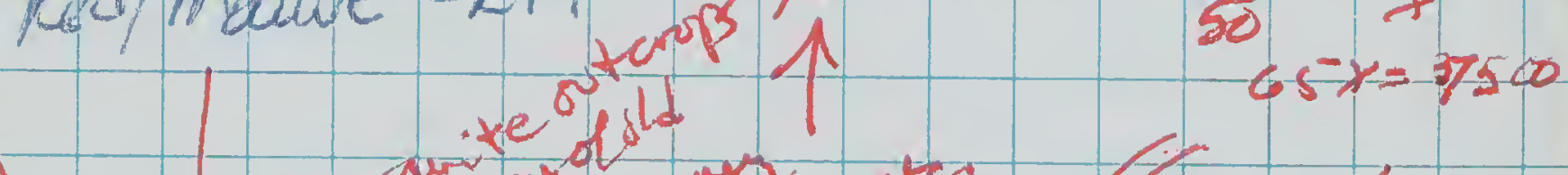

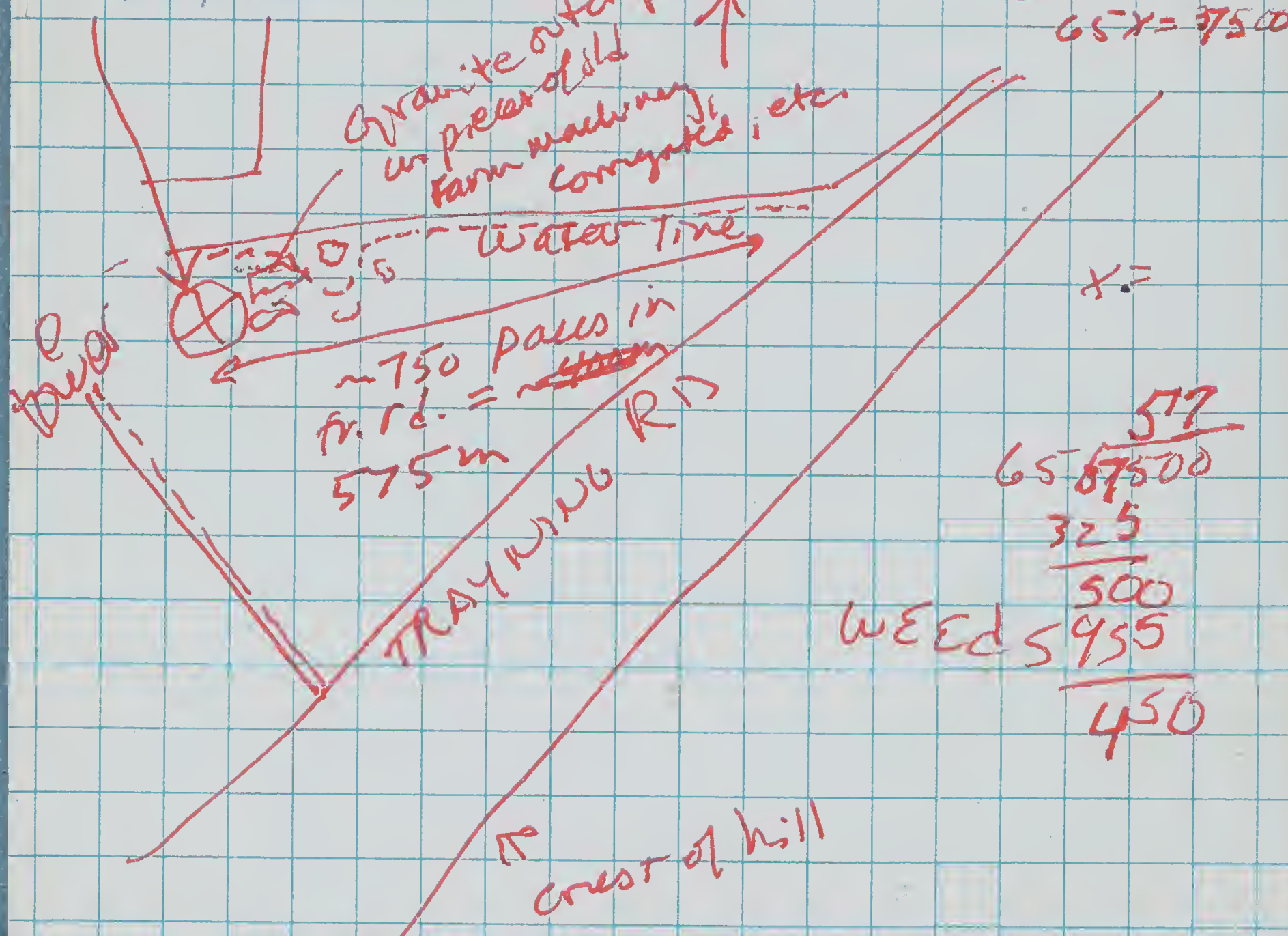


- I vetted I q Refouswister, imm. Red-cupped Robin, breedizo bW Triller, 3 Y-RT-bill, i w. warbles. q Ruf Whister bueded af site in weeds

Calma water live $2550 \mathrm{~m}$ W. of whar it ceits awoy hom the pured $\mathrm{ND}$ )

$$
\begin{aligned}
& \text { OR/Wh- Right } \\
& \text { Wh/metal - left (\#033-27066) }
\end{aligned}
$$

Note: Thin is nst The of assocrated w. the of (Red (chart-rT) at the far \$W avwer of weeds (Milltop hear captared The portino of

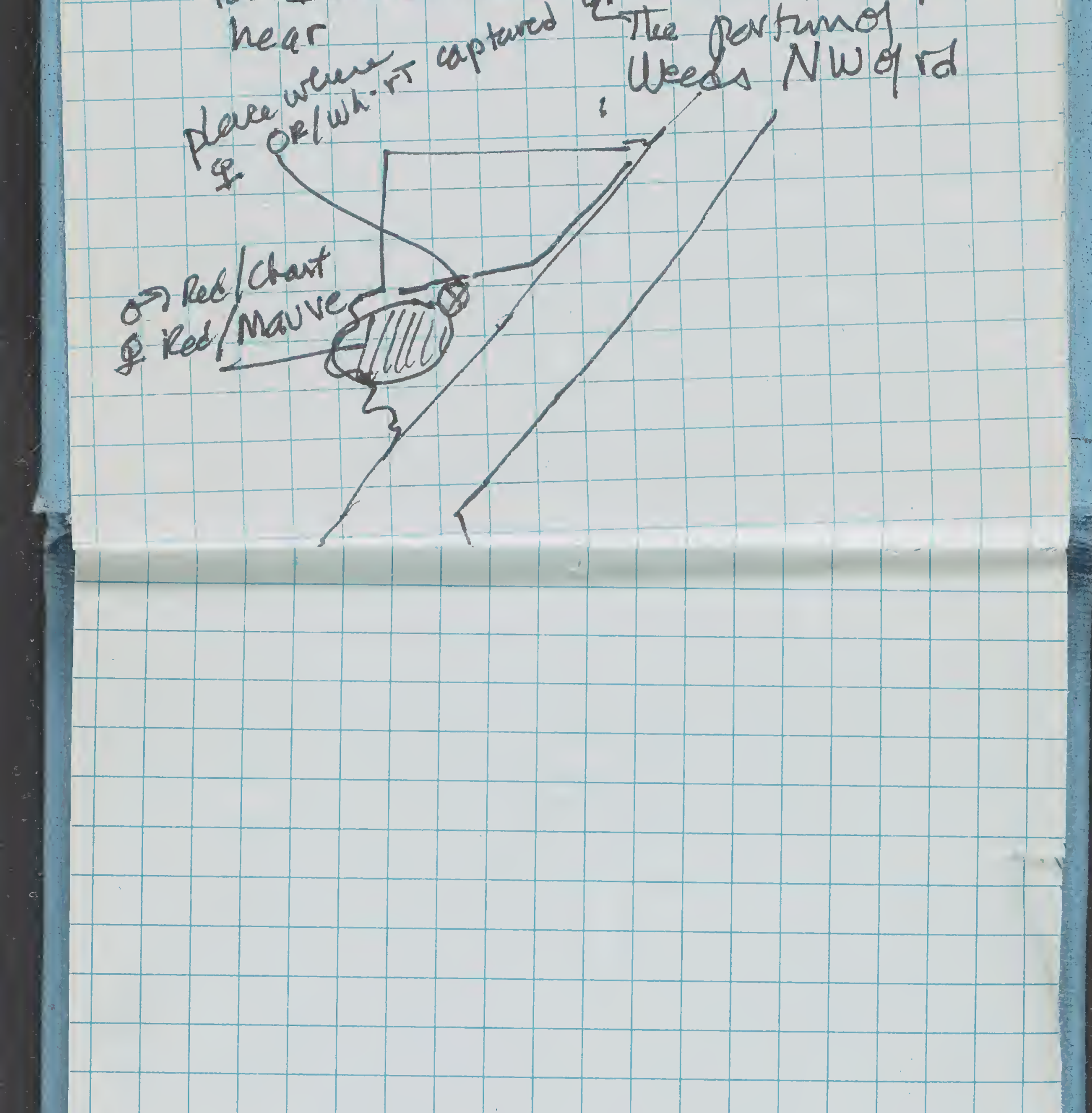




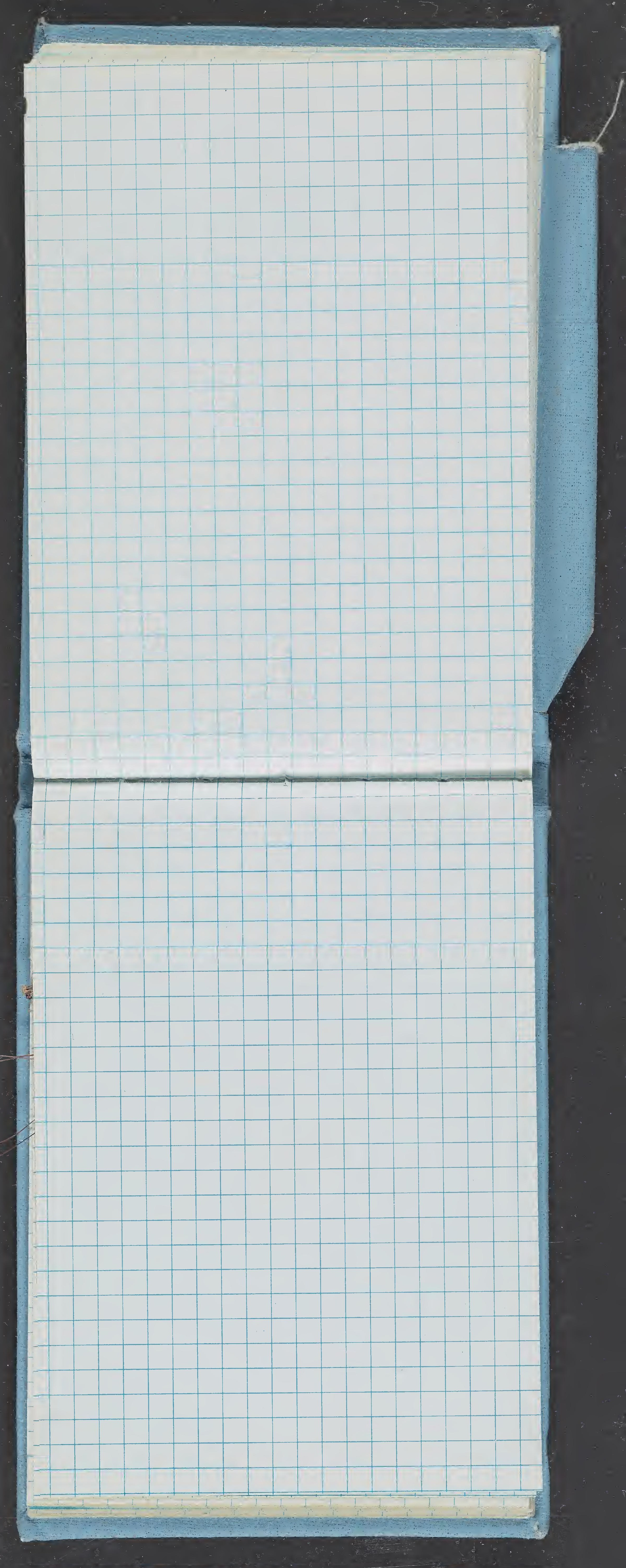




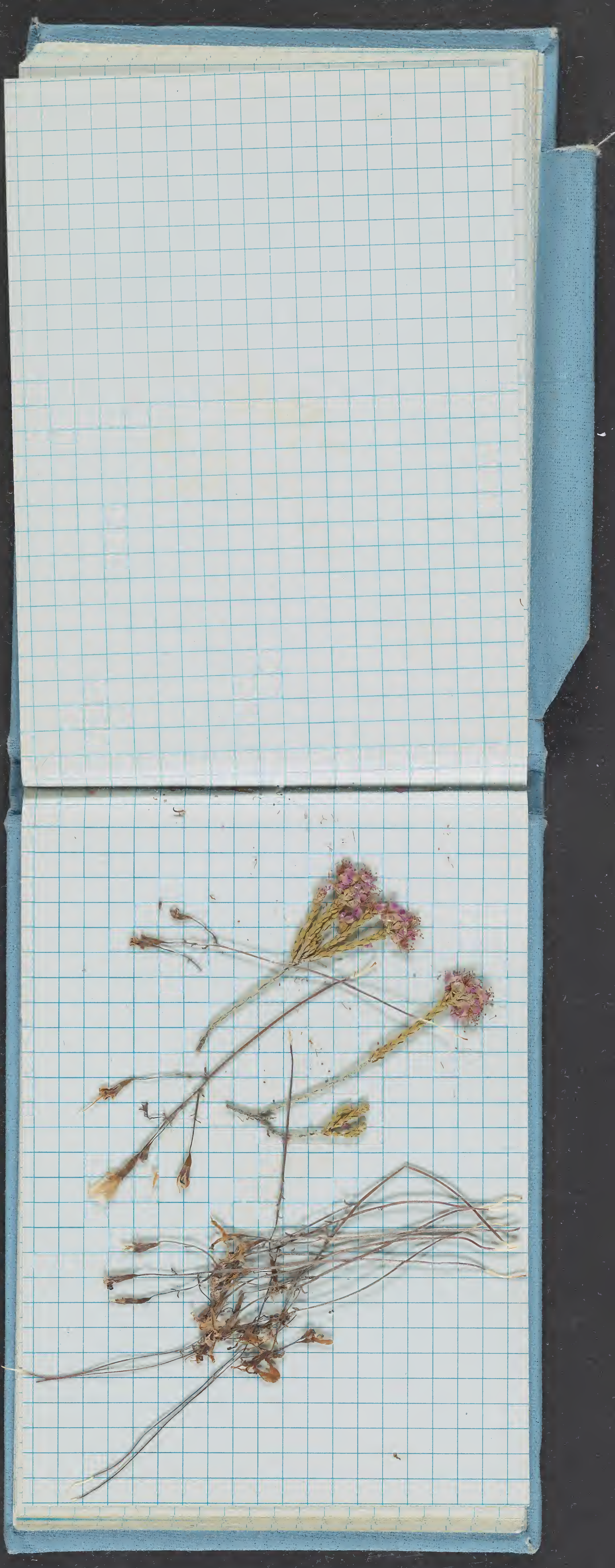




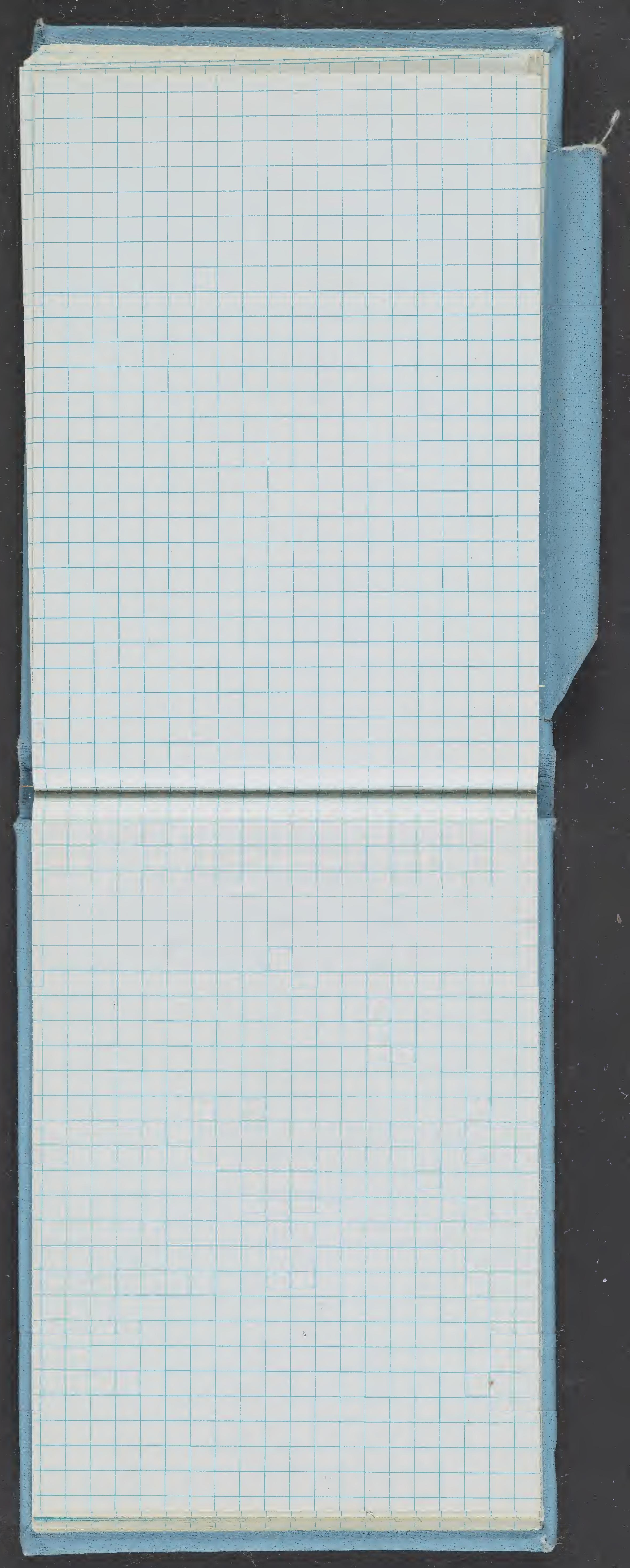




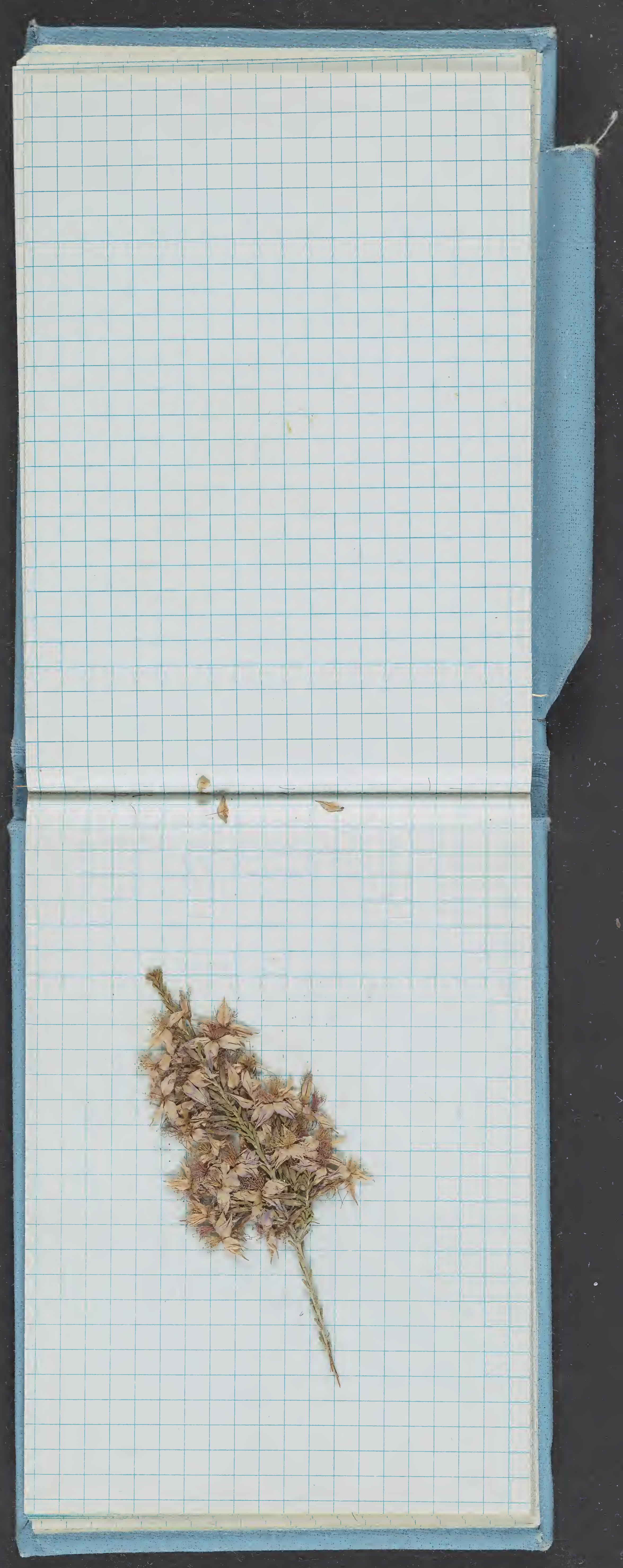




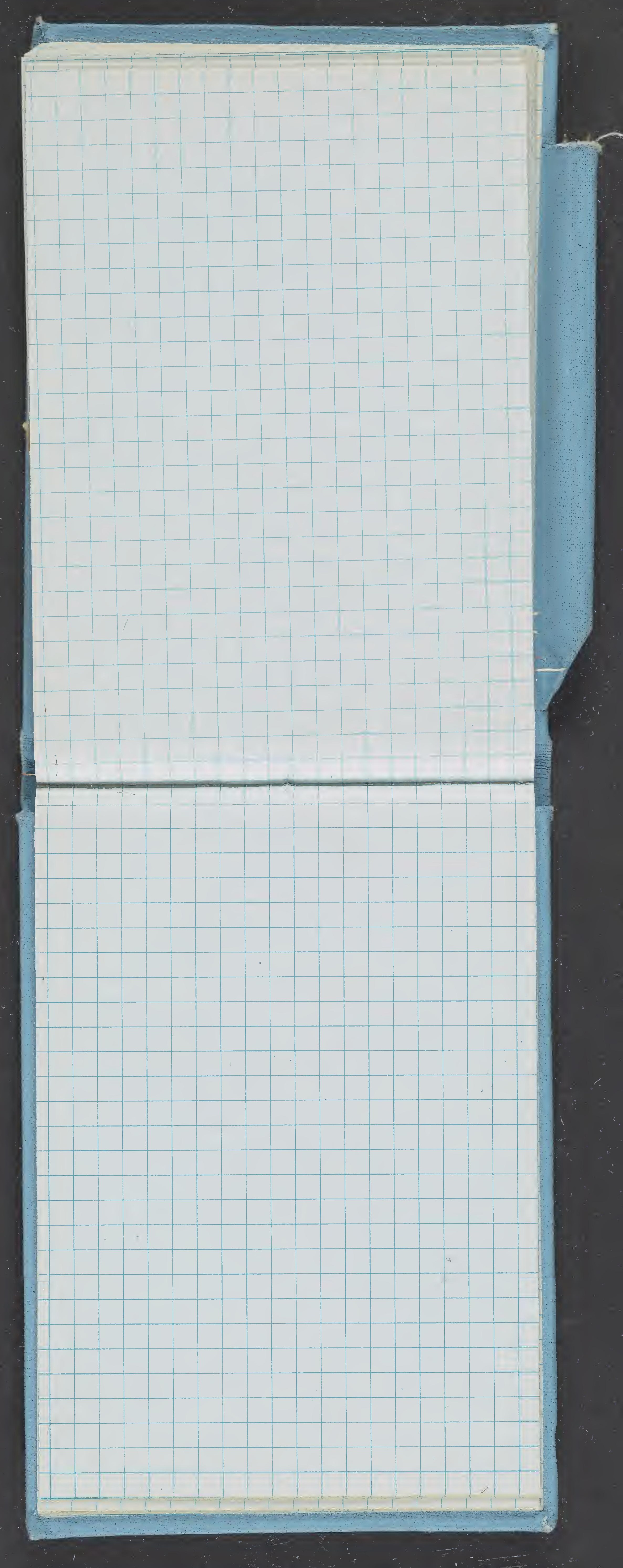




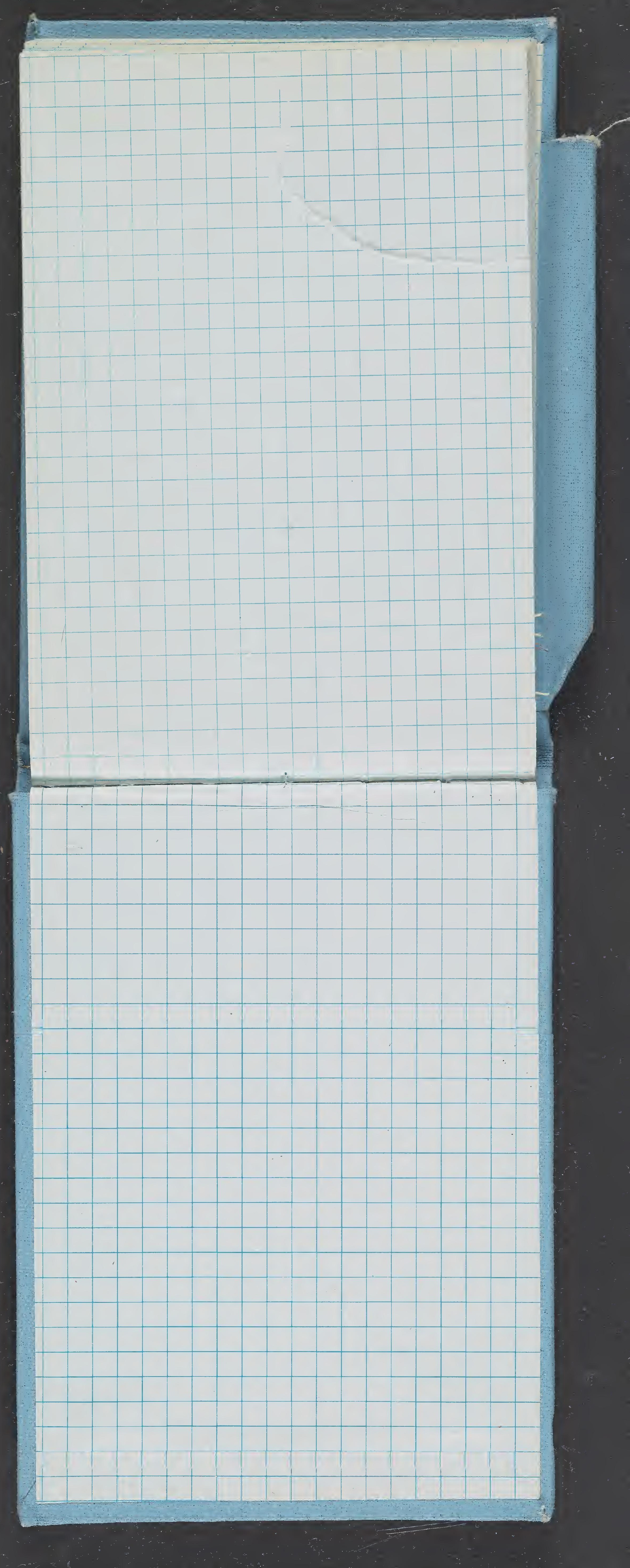


